\title{
DIRETIVAS ANTECIPADAS DE VONTADE E PESSOAS COM DEFICIÊNCIA: EXERCÍCIO DA AUTONOMIA PRIVADA EXISTENCIAL
}

\author{
Iara Antunes de Souza*
}

\begin{abstract}
RESUMO
O objetivo é explorar, de modo argumentativo, a (im)possibilidade das pessoas com deficiência realizarem suas diretivas antecipadas de vontade, para, mediante vertente metodológica teóricodogmática, esboçar possível papel da autonomia privada existencial. A hipótese é de que diante do atual ordenamento jurídico, é direito fundamental da pessoa com deficiência o exercício pleno de decisões sobre sua vida, em especial no que tange à saúde, respeitando as repercussões do Estatuto da Pessoa com Deficiência. Trata-se de pesquisa multidisciplinar, afeta ao microssistema do biodireito. A relevância evidencia-se pela possibilidade promoção dos direitos existenciais da pessoa com deficiência em concretização aos seus direitos fundamentais.
\end{abstract}

Palavras-chave: Diretivas Antecipadas de Vontade; Deficiência; Autonomia Privada; Biodireito.

\section{ANTICIPATED DIRECTIVES AND DISABLED PERSON: EXERCISE OF EXISTENTIAL PRIVATE AUTONOMY}

\begin{abstract}
The objective is to explore, in an argumentative way, the (im)possibility of disabled person to carry out their anticipated directivies, in order, through theoretical-dogmatic methodological aspects, the possible role of existential private autonomy. The hypothesis is the legal system, it is the fundamental right of the disabled person to fully exercise decisions about their life, especially health decisions, the repercussions in disabled person's statute. It is a multidisciplinary research, which comprises concepts of the microsystem of the biolaw. The relevance is evidenced by the possibility of promoting the existential rights of disabled person in realizing their fundamental rights.
\end{abstract}

Keywords: Anticipated Directives; disabled person; Private Autonomy; biolaw.

\section{INTRODUÇÃO}

\footnotetext{
* Doutora e Mestra em Direito Privado pela PUC Minas. Professora da graduação em Direito e do Mestrado acadêmico "Novos Direitos, Novos Sujeitos" da Universidade Federal de Ouro Preto - UFOP. Pesquisadora do Centro de Estudos em Biodireito - CEBID/UFOP. AUXÍLIO PESQUISADOR UFOP 2017-2020. Endereço: Universidade Federal de Ouro Preto. Campus Universitário Morro do Cruzeiro, S/N, Morro do Cruzeiro, Ouro Preto - MG, CEP 35400-000. E-mail: iara@ufop.edu.br
} 
$\mathrm{Na}$ atualidade, as questões conflitantes acerca da terminalidade da vida estão em voga, de forma que a eutanásia, o suicídio assistido e a ortotanásia, por exemplo, estão, a todo tempo, permeando os noticiários e estudos bioéticos e biojurídicos.

Nesse passo, as diretivas antecipadas de vontade - DAV, que permitem à pessoa, diante de questões relacionadas à sua saúde e tratamento, o exercício da sua autonomia privada existencial de forma a recusar certos tratamentos ou terapias, bem como escolher, dentre aqueles possíveis e disponíveis, o que acha adequado ganha espaço.

Entretanto, a tradição do direito privado brasileiro exige a personalidade e a capacidade civil para exercício pleno da autonomia privada. Em sua teoria das capacidades, o Código Civil relegava às pessoas com deficiência, em especial as de cunho mental, mas também aos surdos-mudos e quiçá aos cegos, a condição de incapacidade civil que, portanto, em um ideário de morte civil, as alijavam do direito de exercício da autonomia privada, inclusive da existencial.

Fala-se no passado, pois, desde janeiro de 2016 o direito brasileiro conta com uma lei específica, qual seja, a Lei n. 13.146 (BRASIL, 2015), que "Institui a Lei Brasileira de Inclusão da Pessoa com Deficiência" - LBI - que é conhecida como Estatuto da Pessoa com Deficiência - EPD, e alterou a teoria das capacidades no direito brasileiro. Ela efetiva a Convenção Internacional sobre os Direitos Humanos das Pessoas com Deficiência - Carta de Nova Iorque, da qual o Brasil é signatário, e que se incorporou ao Direito brasileiro por meio do Decreto n. 6.949, de 25 de agosto de 2009 (BRASIL, 2009), e, considerando que sua aprovação se deu nos termos do disposto no $\S 3^{\circ}$ do artigo $5^{\circ}$ da Constituição da República de 1988 (BRASIL, 1988), a dita convenção tem status de norma constitucional. Assim, tem-se no Brasil atualmente um microssistema jurídico de proteção e promoção da pessoa com deficiência.

O que se percebe, portanto, é que os direitos das pessoas com deficiência são normas fundamentais, constitucionalmente asseguradas desde 2009. O que o estatuto fez foi, ao ser introduzido no ordenamento legal, buscar a mudança da cultura de direitos relativos às pessoas com deficiência (SOUZA, 2018), incluindo, dentro do interesse específico desse artigo, sua capacidade civil.

Por essa razão, esse texto ocupa-se da intenção de esboçar reflexões acerca da possibilidade de exercício de autonomia privada existencial das pessoas com deficiência junto às diretivas antecipadas de vontade. Logo, a hipótese é de que, diante do atual ordenamento 
jurídico, é direito fundamental da pessoa com deficiência o exercício pleno de decisões sobre sua vida, em especial no que tange às suas decisões de saúde, respeitando as repercussões do Estatuto da Pessoa com Deficiência.

Prevalece, no trabalho, a vertente metodológica teórico-dogmática, para, a partir do sistema jurídico posto, pela via da coleta de dados em fonte bibliográfica e documental, promover, de modo argumentativo, o possível desenho das expressões da autonomia privada existencial das pessoas com deficiência diante das diretivas antecipadas de vontade.

Trata-se de pesquisa multidisciplinar, que compreende conceitos do microssistema do biodireito. A relevância desses escritos evidencia-se pela possibilidade de promoção dos direitos existenciais da pessoa com deficiência em concretização aos seus direitos fundamentais, nos termos internacionais e constitucionais.

\section{AS DIRETIVAS ANTECIPADAS DE VONTADE}

Em algumas situações na terminalidade da vida não é possível a aferição direta da vontade da pessoa, isto é, ela não pode manifestar, por si só, acerca dos procedimentos médicos que gostaria ou não de se submeter. Tais situações práticas não são poucas, tais como o coma, os estados vegetativos, a perda de consciência etc., todas afetas à bioética e ao biodireito.

Para que se possa aferir, nessas circunstancias a vontade da pessoa, ainda que de forma prévia, apresenta-se as diretivas antecipadas de vontade ou, conforme prefere Luciana Dadalto Penalva (2009, p. 526), as declarações prévias de vontade, como o meio apto a, de antemão, deixar consignado os tratamentos e intervenções médicas aos quais o/a paciente deseja ou não se submeter caso, por alguma circunstância, não possa, por si só, manifestar a dita vontade.

As diretivas antecipadas de vontade são conhecidas no Brasil, também, como testamento vital. Entretanto, tal nomenclatura, não é a mais adequada, considerando que este instituto tem o condão de surtir efeitos para após a morte da pessoa (CATEB, 2011, p.157), enquanto que aquelas visam cumprir efeitos antes da morte.

Logo, as diretivas antecipadas de vontade são um negócio jurídico "[...] unilateral, personalíssimo, gratuito e revogável.” (PENALVA, 2009, p. 526), cuja produção de efeitos se dará durante a vida da pessoa.

Como espécie de diretivas antecipadas de vontade, apresenta-se o mandato duradouro, onde a pessoa nomeia outrem para decidir, em seu lugar, mas considerando suas próprias 
convicções, os tratamentos a serem realizados (PENALVA, 2009, p.524), durante o período em que estiver inconsciente ou acometida por anomalia psíquica que comprometa severamente o seu discernimento (TEIXEIRA;RIBEIRO, 2009, p.8) ou sua capacidade de expressão de vontade, como prefere o Código Civil em sua atual redação.

Em qualquer caso, por se tratarem de negócio jurídico, as diretivas antecipadas de vontade, para encontrarem validade jurídica, especialmente na seara médica, devem preencher os requisitos do artigo $104^{1}$ do Código Civil: agente capaz, objeto lícito, forma prescrita ou não defesa em lei.

Quanto ao objeto, as diretivas antecipadas descrevem os tratamentos e procedimentos médicos aos quais a pessoa deseja ou não, antecipadamente, se submeter (SOUZA, 2013). Frisa-se que a prática encontra respaldo junto ao Conselho Federal de Medicina, que na Resolução n. ${ }^{o}$ 1.995/2012 determinou que diante da impossibilidade de manifestação de vontade do/a paciente quando da necessidade da prática médica, o/a médico/a deve levar em consideração a vontade anteriormente manifestada, que se sobreporá a de qualquer outra pessoa, exceto a que fora designada em mandato duradouro, para o especifico fim (SÁ; NAVES, 2012). Por se tratar de objeto vinculado à saúde e ao próprio corpo, logo, direito de personalidade, as diretivas antecipadas de vontade têm conteúdo existencial que demandará, assim, manifestação de vontade de cunho existencial.

Quanto à forma, diferente do testamento que tem sua formalidade prescrita em lei, sendo, como no público, por vezes, solene; as diretivas antecipadas de vontade têm forma livre. Entretanto, para fins de prova, é adequada a utilização da forma escrita. Tanto é assim, que Maria de Fátima Freire de Sá e Bruno Torquato de Oliveira Naves defendem que as diretivas antecipadas são legitimadas no Brasil como:

[...] negócio jurídico, as diretivas estão subordinadas ao atendimento de requisitos nos planos de existência, validade e eficácia. Nesse ponto, acreditamos que a declaração e vontade deva ser feita por pessoa capaz, através de instrumento público ou escrito particular, com reconhecimento de firma e endosso testemunhal (SÁ; NAVES, 2018, p. 397).

Por fim, quanto a ser o "agente capaz", entende-se a capacidade como aptidão para o exercício da autonomia privada, ou seja, a autodeterminação, seu discernimento ou

\footnotetext{
${ }^{1}$ Art. 104. A validade do negócio jurídico requer: I - agente capaz; II - objeto lícito, possível, determinado ou determinável; III - forma prescrita ou não defesa em lei.
} 
possibilidade de expressão de vontade, é aquela sem qualquer condicionante que a vicie, tais como o erro, dolo, coação, estado de perigo e lesão.

Nesse passo, perquiri-se: de qual autonomia se fala e qual é esse "agente", ou seja, pode ser a pessoa com deficiência?

\section{A AUTONOMIA PRIVADA EXISTENCIAL}

Autonomia privada configura-se como a capacidade das pessoas de se autogovernar, de tomar decisões acerca de si, sem sofrer imposições externas. Pode-se resumir seu conteúdo por meio da expressão autodeterminação, que é fundamentada, por sua vez, na dignidade da pessoa humana. Trata-se de princípio biojurídico, que legitima às atuações bio-médicocientíficas em relação à pessoa.

A autonomia a qual se refere é a que se denomina como autonomia privada. Prefere-se essa denominação em contraponto à autonomia da vontade, eis que esta "[...] possui uma conotação psicológica, ligada ao momento do Estado Liberal em que a vontade ocupava lugar privilegiado, sendo suficiente para criar Direito, cabendo ao Estado apenas sancioná-la." (SÁ; NAVES, 2018, p.42). Sendo assim, o Estado não interferia na manifestação de vontade das partes e nem mesmo nos efeitos dela decorrentes. Já a autonomia privada encontra no direito limitações de conteúdo e eficácia (FARIA, 2007, p. 70). Ela possui uma conotação mais objetiva, concreta e real.

Entretanto, o exercício dessa autonomia exige, segundo o direito, a personalidade e capacidade.

A personalidade é tida em duas acepções: uma subjetiva e outra objetiva (FIUZA, 2007, p. 171). Na perspectiva objetiva, personalidade é um conjunto de atributos humanos que merecem proteção jurídica. Logo, a personalidade é o objeto do direito, junto aos direitos humanos, dignidade da pessoa humana e direitos da personalidade. Assim, o direito ao próprio corpo e o conceito existencial de saúde, são acepções existenciais. Já na acepção subjetiva, a personalidade liga-se à ideia de capacidade, sendo entendida, conforme preceitua Francisco Amaral (2006, p.248), como a titularidade de direitos e deveres ínsitos a qualquer ser humano que nasce com vida, nos termos dos artigos $1^{\circ}$ e $2^{\circ}$ do Código Civil Brasileiro e às pessoas jurídicas, confundindo-se com a capacidade de direito ou de gozo, eis que capacita para ser sujeito nas relações jurídicas. Trata-se, portanto, de atributo jurídico. 
Contudo, nem toda pessoa tem aptidão para exercer pessoalmente os atos da vida civil, ou seja, não tem capacidade de fato ou de exercício. Esta é adquirida, nos termos do artigo $5^{\circ}$ do Código Civil, quando do alcance da idade de 18 (dezoito) anos completos ou no caso de emancipação, desde que não haja outra hipótese de incapacidade relativa, prevista nos artigos $4^{\mathrm{o}}$ do mesmo Código. Dessa forma, quando a pessoa passa a reunir as capacidades de direito (gozo) e de fato (exercício), diz-se que ela goza de capacidade civil plena (GAGLIANO; PAMPLONA FILHO, 2009, p. 88).

Doutro lado, ainda que possua a capacidade de direito ou gozo atribuída junto à personalidade jurídica, os ditos incapazes pelo Código Civil, ainda que maiores de idade, não poderão, por si só, exercer os atos da vida civil, necessitando de um representante ou assistente a depender da total ou parcial impossibilidade de manifestação de vontade para o ato.

A expressão externa da autonomia se dá por meio da manifestação de vontade. Esta, para ter validade jurídica, em negócio jurídico, como é o caso das diretivas antecipadas de vontade, como já exposto, deve preencher os requisitos do artigo 104 do Código Civil. Dentre eles, encontra-se a necessidade de a pessoa ser capaz.

Contudo, diante de tudo o que fora exposto até agora, verifica-se que a capacidade exigida para a realização do negócio jurídico junto às diretivas antecipadas de vontade, não é somente a capacidade civil abstratamente atribuída pelo Código Civil. É necessário que a pessoas manifeste discernimento ou possibilidade de expressão de vontade e competência ${ }^{2}$ para decisões acerca de sua vida, saúde e tratamento.

Nesse passo justifica-se a revisão das teorias das capacidades junto ao ordenamento jurídico brasileiro, perpetrada pelo Estatuto da Pessoa com Deficiência junto ao Código Civil de 2002, diante dos ditames da Convenção Internacional sobre os Direitos Humanos das Pessoas com Deficiência - Carta de Nova Iorque, eis que busca a concretização os anseios constitucionais, em especial, proteção e promoção efetivas da dignidade humana e o fomento da construção pessoal da personalidade e pessoalidade (SÁ; MOUREIRA, 2012, p.32) em especial das pessoas com deficiência.

É necessário dar voz às pessoas com deficiência, principalmente nas questões existenciais, nos termos do Código Civil, eis que, "Direitos de personalidade não podem ser exercidos pelo curador, eis que intransmissíveis e, portanto, autorreferenciais." (SÁ; MOURA, 2011, p.139). Nesse sentido,

\footnotetext{
${ }^{2}$ Competência é o exercício da autonomia para as questões médicas (MOREIRA; OLIVEIRA, 2008).
} 
Atualmente, em obediência ao princípio da dignidade da pessoa humana, a vontade deve ser considerada como manifestação para o pleno desenvolvimento da personalidade humana, e deve ser sempre respeitada, ainda quando o manifestante seja pessoa considerada juridicamente incapaz (ARAÚJO; NUNES, 2009, p. 47).

A construção da autonomia privada e sua possibilidade de exercício em modelos estanques é atributo de uma visão patrimonialista ${ }^{3}$ do direito que não se justifica na atualidade. A dignidade da pessoa humana, nos termos do artigo $1^{\circ}$, III da Constituição da República de 1988, erradia sua força normativa a todo o direito de forma a concretizá-la, inclusive no exercício da autonomia, que, então, ganha a adjetivação de existencial. Afinal: "Como elemento da autonomia a existência digna é construída por meio do exercício dialógico das racionalidades autônomas por meio do exercício das racionalidades autônomas, o que pressupõe a inclusão de cada sujeito no espaço público construído por todos.” (POMPEU, 2015, p.121).

Assim, considerando que a eleição de vida boa e critérios de saúde, o que envolve os procedimentos médicos aos quais a pessoa deseja ou não se submeter; considerando, ainda, que somente é legitimada a intervenção de um terceiro (médico/a) sobre a pessoa mediante seu consentimento; em existindo discernimento ou possibilidade de expressão de vontade e competência, demonstra-se a importância da autonomia existencial.

\section{A PESSOA COM DEFICIÊNCIA}

O EPD (BRASIL, 2015) prevê em seu artigo $2^{\circ}$ :

Art. $2^{\circ}$ Considera-se pessoa com deficiência aquela que tem impedimento de longo prazo de natureza física, mental, intelectual ou sensorial, o qual, em interação com uma ou mais barreiras, pode obstruir sua participação plena e efetiva na sociedade em igualdade de condições com as demais pessoas. (BRASIL, 2015).

Logo, a pessoa com deficiência é aquela que encontra barreiras que a impedem de exercer os seus direitos em igualdade de condições com as demais pessoas. Essas barreiras podem ser cognitivas que impactam, em especial na deficiência mental e em graus diversos,

\footnotetext{
3 “"...] há patente diversidade de fundamentação dos atos de autonomia, tendo-se como parâmetro o tipo de situações, definidas pelas funções a serem realizadas: se patrimonial repousa na livre iniciativa, prevista pelo art. 170, CF/88;30 se existencial, sua base está na dignidade da pessoa humana ( $\operatorname{art.} 1^{\circ}, \mathrm{III}, \mathrm{CF}$ ) e liberdade (art. $5^{\circ}$, caput, CF). A diferença de fundamento interfere na coerência e legitimidade dos argumentos utilizados para qualificação da situação jurídica.” (TEIXEIRA, 2018, p.86).
} 
junto à possibilidade de manifestação de vontade ou no discernimento e na competência para decisões médicas relativas à saúde.

Não há uma deficiência inerente à pessoa e nem modelos estanques de deficiência. De fato, o relator do projeto de lei que deu origem ao EPD assim se manifestou:

Acolhemos a sugestão da Câmara dos Deputados. Não há uma deficiência intrínseca. A deficiência decorre de uma característica atípica da pessoa em interação com barreiras de diversas categorias existentes na sociedade. Por isso, o conceito de deficiência está em permanente evolução, uma vez que cada vez mais se estudam e se descobrem condições raras de indivíduos que os impedem de exercer plenamente suas potencialidades, dada a existência dessas barreiras mencionadas. (FARIA, 2015).

As espécies de deficiência, portanto, não podem ser catalogadas. Sua verificação, deve ser feita por equipe multidisciplinar, conforme disposto no $\S 1^{\circ}$ do Artigo $2^{\circ}$ do EPD, em análise biopsicossocial. Logo, não basta um atestado médico com a indicação da CID (classificação internacional das doenças) para que a deficiência seja identificada. A deficiência é modelo social, não se admitindo o engessamento de tipos, inadmitindo um modelo estático.

$\mathrm{O} \S 2^{\mathrm{ou}^{4}}$ do artigo $2^{\mathrm{o}}$ do Estatuto da Pessoa com Deficiência prevê que um ato do Poder Executivo deve criar o instrumento de avaliação da deficiência, que, nos termos do artigo 84, IV $^{5} 11$ da Constituição da República, deveria ser um Decreto Presidencial. Não houve a edição de dita norma regulamentadora após o Estatuto da Pessoa com Deficiência. O que houve foi a edição de uma Resolução n. ${ }^{\circ}$ 01/2020 da Secretaria Nacional dos Direitos da Pessoa com Deficiência do Ministério da Mulher, da Família e dos Direitos Humanos, publicada no Diário Oficial da União em 10 de março de 2020, para “Aprovar o Índice de Funcionalidade Brasileiro Modificado (IFBrM) como instrumento adequado de avaliação da deficiência a ser utilizado pelo Governo Brasileiro, conforme prevê o Parágrafo $2^{\circ}$ do Artigo $2^{\circ}$ " da aludida lei.

Assim, não é possível falar em aplicabilidade do Decreto n. ${ }^{\circ} 3.298 / 99$, que, baseado no modelo médico de deficiência, traz as hipóteses de deficiência em seu artigo $4^{\circ}$, inciso IV ${ }^{6}$.Tal

\footnotetext{
${ }^{4} \S 2^{\circ}$ O Poder Executivo criará instrumentos para avaliação da deficiência.

${ }^{5}$ Art. 84. Compete privativamente ao Presidente da República: [...] V - sancionar, promulgar e fazer publicar as leis, bem como expedir decretos e regulamentos para sua fiel execução; [...].

${ }^{6}$ Art. 4o É considerada pessoa portadora de deficiência a que se enquadra nas seguintes categorias:[...]

I - deficiência física - alteração completa ou parcial de um ou mais segmentos do corpo humano, acarretando o comprometimento da função física, apresentando-se sob a forma de paraplegia, paraparesia, monoplegia, monoparesia, tetraplegia, tetraparesia, triplegia, triparesia, hemiplegia, hemiparesia, ostomia, amputação ou ausência de membro, paralisia cerebral, nanismo, membros com deformidade congênita ou adquirida, exceto as deformidades estéticas e as que não produzam dificuldades para o desempenho de funções; (Redação dada pelo Decreto $n^{\circ}$ 5.296, de 2004)
} 
Decreto, entende-se, fere frontalmente o modelo social que é o atual de deficiência, bem como os anseios da Carta de Nova Iorque e, portanto, do Estatuto da Pessoa com Deficiência, de modo que, por serem de status constitucional, é eivado de inconstitucionalidade (NOGUEIRA; SOUZA, 2019).

Assim, pode-se compreender que é pessoa com deficiência aquela que tem impedimento de longo prazo, de natureza física, mental, intelectual ou sensorial; e que, em interação com uma ou mais barreiras, tem obstruída sua participação plena e efetiva na sociedade em igualdade de condições com as demais pessoas; sendo ditos impedimentos e barreiras aferidos por meio de análise biopsicossocial por equipe multidisciplinar (NOGUEIRA; SOUZA, 2018).

Logo, o que o Estatuto da Pessoa com Deficiência traz é a despatologização da deficiência e, consequentemente, da incapacidade. Ora, a doença não é causa necessária de deficiência e nem àquela e nem essa, por si só, são causa de incapacidade. Seu grande avanço foi, de fato, retirar de uma vez por todas do ordenamento jurídico a possibilidade de ligar o transtorno e a deficiência mental, como critério, por si só, de incapacidade e garantir o exercício da capacidade na maior medida (SOUZA, 2018) de possibilidade de expressão de vontade.

A capacidade é a regra, sempre foi, e agora não há como defender posição diferente diante do exposto no artigo $6^{\circ}$ do Estatuto da Pessoa com Deficiência, aplicado diretamente

II - deficiência auditiva - perda bilateral, parcial ou total, de quarenta e um decibéis (dB) ou mais, aferida por audiograma nas frequiências de $500 \mathrm{HZ}, 1.000 \mathrm{HZ}, 2.000 \mathrm{~Hz}$ e $3.000 \mathrm{~Hz}$; (Redação dada pelo Decreto $\mathrm{n}^{\circ} 5.296$, de 2004)

III - deficiência visual - cegueira, na qual a acuidade visual é igual ou menor que 0,05 no melhor olho, com a melhor correção óptica; a baixa visão, que significa acuidade visual entre 0,3 e 0,05 no melhor olho, com a melhor correção óptica; os casos nos quais a somatória da medida do campo visual em ambos os olhos for igual ou menor que 60o; ou a ocorrência simultânea de quaisquer das condições anteriores; (Redação dada pelo Decreto nº 5.296, de 2004)

IV - deficiência mental - funcionamento intelectual significativamente inferior à média, com manifestação antes dos dezoito anos e limitações associadas a duas ou mais áreas de habilidades adaptativas, tais como:

a) comunicação;

b) cuidado pessoal;

c) habilidades sociais;

d) utilização dos recursos da comunidade; (Redação dada pelo Decreto nº 5.296, de 2004)

e) saúde e segurança;

f) habilidades acadêmicas;

${ }^{7}$ Art. $6^{\circ}$ A deficiência não afeta a plena capacidade civil da pessoa, inclusive para:

I - casar-se e constituir união estável;

II - exercer direitos sexuais e reprodutivos;

III - exercer o direito de decidir sobre o número de filhos e de ter acesso a informações adequadas sobre reprodução e planejamento familiar;

IV - conservar sua fertilidade, sendo vedada a esterilização compulsória;

$\mathrm{V}$ - exercer o direito à família e à convivência familiar e comunitária; e 
aos direitos existenciais da pessoa (incluindo saúde e família), nem mesmo diante da presença de uma deficiência verificada por uma equipe multidisciplinar. Este artigo é completado pelo artigo 84 do mesmo Estatuto que prevê em seu caput: "Art. 84. A pessoa com deficiência tem assegurado o direito ao exercício de sua capacidade legal em igualdade de condições com as demais pessoas.” (BRASIL, 2015). Essas normas corroboram os princípios da Carta de Nova Iorque, em especial o previsto no artigo 12, 2: “2. Os Estados Partes reconhecerão que as pessoas com deficiência gozam de capacidade legal em igualdade de condições com as demais pessoas em todos os aspectos da vida." (BRASIL, 2009).

Avança-se mais. Em que pese as modificações na teoria da capacidades civis terem sido perpetradas pelo Estatuto da Pessoa com Deficiência, a incapacidade civil, na prática, diante da reforma e dos anseios já apresentados pelos estudiosos do direitos anteriores a ela, como Maria de Fátima Freire de Sá e Diogo Luna Moureira (2011), não se vincula sequer à deficiência. A previsão atual do Código Civil de 2002 é:

\footnotetext{
Art. 3o São absolutamente incapazes de exercer pessoalmente os atos da vida civil os menores de 16 (dezesseis) anos. (Redação dada pela Lei no 13.146, de 2015)

I - (Revogado); $\quad$ (Redação dada pela Lei no 13.146, de 2015)

II - (Revogado); $\quad$ (Redação dada pela Lei no 13.146, de 2015)

III - (Revogado). (Redação dada pela Lei no 13.146, de 2015)

Art. 4o São incapazes, relativamente a certos atos ou à maneira de os exercer: (Redação dada pela Lei no 13.146 , de 2015)

I - os maiores de dezesseis e menores de dezoito anos;

II - os ébrios habituais e os viciados em tóxico; (Redação dada pela Lei $\mathbf{n}^{\circ}$

13.146, de 2015)

III - aqueles que, por causa transitória ou permanente, não puderem exprimir sua vontade; (Redação dada pela Lei $n^{\circ}$ 13.146, de 2015)

IV - os pródigos.

Parágrafo único. A capacidade dos indígenas será regulada por legislação especial. (Redação dada pela Lei no 13.146, de 2015). (BRASIL, 2002, grifos nossos).
}

Da leitura do artigos $4^{\circ}$ e $5^{\circ}$ do Código Civil de 2002, infere-se que não há causas de saúde mental para fins de incapacidade absoluta e que, quanto à incapacidade relativa, substitui-se a ideia de falta de discernimento para o exercício dos atos da vida civil, para o critério de impossibilidade de expressão de vontade, que pode ou não estar atrelado a uma doença ou a uma deficiência. Logo, afirma-se, pode existir mesmo na ausência de uma doença ou deficiência. A definição da incapacidade, segundo ditames do Estatuto da Pessoa com

VI - exercer o direito à guarda, à tutela, à curatela e à adoção, como adotante ou adotando, em igualdade de oportunidades com as demais pessoas. (BRASIL, 2015). 
Deficiência, é competência de uma equipe multidisciplinar, assemelhando-se, portanto, à política pública brasileira de tratamento de saúde mental (SOUZA, 2018). A esta equipe caberá muito mais do que o diagnóstico de uma doença mental ou da verificação de uma deficiência. Cabe a ela sim e primordialmente avaliar se, excepcionalmente, a doença, a deficiência ou qualquer outro fato externo ou interno afeta a autodeterminação da pessoa, ou seja, afeta a sua possibilidade de expressão de vontade para exercer os atos da vida civil ou, no caso das questões de saúde, se afeta a competência para tomada de decisões médicas.

O papel da equipe multidisciplinar e sua importância para o reconhecimento da incapacidade civil é relevante e já reconhecido pelo judiciário. De fato, a prova pericial juntada ao processo oriunda dos laudos da equipe multidisciplinar são o que, de fato, determina ou não a capacidade da pessoa. O juiz, apesar de não se vincular ao lado, não tem competência técnica para determinar ou não a incapacidade diante da audiência de entrevista de um curatelando (SOUZA, 2018). Nesse sentido, decidiu o Tribunal de Justiça do Estado de Minas Gerais:

\footnotetext{
Nesse espeque, ao contrário dos argumentos apresentados pelo Representante do Ministério Público de que o interditando demonstra capacidade para reger sua própria pessoa e os bens que porventura possua, considero que o laudo pericial aponta para conclusão em sentido contrário, conforme se denota da resposta aos quesitos transcritos alhures.

Afirma o douto Magistrado que, em interrogatório judicial, o interditando detinha condições de exprimir de maneira clara e lúcida seus pensamentos e vontades, o que evidenciaria que possui plena capacidade para gerir sua pessoa e seus bens. Destaca, ainda, que "o interditando não possui doença mental, mas apenas problemas de saúde que não podem ser considerados como fator impeditivo do requerido em reger sua própria pessoa e administrar seus bens".

A meu ver, contudo, tal constatação momentânea não é capaz de afastar o resultado da prova pericial, feita por profissional médico que detém conhecimento técnico para aferir em que medida a doença do paciente interfere nos atos da vida civil.

Com efeito, ainda que a decisão do MM. Magistrado não esteja adstrita ao laudo pericial, certo é que, em demandas desse jaez, a perícia médica oferece relevantes subsídios à formação do convencimento do julgador, na medida em que definirá "se existe causa incapacitante, e, caso positivo, em que grau de extensão compromete o exercício dos atos da vida civil (...)" (Dias, Maria Berenice; in Manual de Direito das Famílias, São Paulo, RT, 2011, p. 624).

Desse modo, em virtude dos pareceres mencionados, entendo que no caso vertente a interdição se revela como medida apropriada[...]. (MINAS GERAIS, 2017).
}

Se a capacidade é a regra, a incapacidade deve ser provada quando existir e nos limites em que existir, devendo as questões existenciais serem exercidas pelas pessoas, ainda que com deficiência, na maior medida do possível. É essa a visão que contempla a promoção da dignidade humana das pessoas com deficiência. 


\section{O EXERCÍCIO DA AUTONOMIA PRIVADA EXISTENCIAL PELAS PESSOAS COM DEFICIÊNCIA JUNTO ÀS DIRETIVAS ANTECIPADAS DE VONTADE}

Diante de uma visão civil constitucional, além de uma ideia prestacional ${ }^{8}$ da saúde, ou seja, que o Estado seja responsável pela saúde de seus cidadãos; vislumbra-se uma ligação direta entre saúde e liberdade. Ou seja, a pessoa tem a liberdade de autonomamente escolher o que é saúde para ela, na medida da possibilidade de compreender as suas escolhas e expressar sua vontade. Nesse sentido:

[...] sua qualificação como direito social é insuficiente para ampla tutela do ser humano, pois a possibilidade de conformação do direito à saúde é tão relevante quanto a efetividade do papel do Estado para eficácia deste direito, razão pela qual se tomou a definição mais moderna de saúde como autogoverno corporal. Em termos de interpretação constitucional, é totalmente possível se entender saúde como direito de liberdade, mesmo a Carta Constitucional de 1988 mantendo seu principal enfoque no caráter prestacional do direito à saúde (TEIXEIRA, 2010, p. 67).

Se a noção de saúde é, também, ligada à liberdade, que decorre da autonomia e da possibilidade de seu exercício, quando se trabalha com a saúde mental, deve se garantir, dentro do que for possível, a emancipação da pessoa para que ela possa ser competente para tomar suas próprias decisões (SOUZA, 2016).

Logo, percebe-se que para o cumprimento do objetivo do tratamento da saúde em geral é necessária a autodeterminação. Pressupõe-se a existência de discernimento ou possibilidade de expressão de vontade e competência. Na relação médico-paciente é necessário que o/a médico/a informe ao/à paciente todas as vicissitudes de seu tratamento para que possa agir mediante autorização dele/a em termo de consentimento livre e esclarecido (SOUZA, 2014). Então, junto ao sistema de saúde público e particular brasileiro, deve-se buscar, na maior medida do possível a emancipação da pessoa como meio de promoção da sua dignidade humana e exercício de sua autonomia existencial.

Nesse passo, perquire-se, a pessoa com deficiência, goza de tal autoderminação? Ainda que se reconheça falta de possibilidade de manifestação de vontade, poder-se-ia, por si só limitar a possibilidade de expressão de autonomia existencial à pessoa com deficiência?

\footnotetext{
${ }^{8}$ Em 1988 e promulgada a Constituição da Republica atual que traz o Direito a saúde como um Direito Fundamental da pessoa humana, junto ao capitulo de Direitos Sociais, artigo 6º prevendo, também, no artigo 196 a ideia prestacional da saúde pelo Estado e mais, nos termos do artigo 198, por meio de um sistema único de saúde - SUS - descentralizado, com atendimento integral e com participação da comunidade.
} 
O artigo 85 caput e o seu parágrafo primeiro ${ }^{9}$ do Estatuto da Pessoa com Deficiência trazem para o sistema de proteção e promoção uma limitação material para curatela, restringindo-se às questões patrimoniais da pessoa, de forma os atos personalíssimos, tais como os ligados ao próprio corpo, sexualidade, matrimônio, privacidade, educação, saúde, trabalho e voto, não podem ser alcançados pela curatela (SOUZA, 2018).

Tal dicção tem o objetivo de afastar a crítica que pairava sobre o ordenamento jurídico civil anterior quando do sistema de interdição/curatela advindo desde o Código Civil de 1916 que importava em morte civil da pessoa que, uma vez interditada de forma absoluta, não era apta a prática de nenhum ato de cunho patrimonial ou existencial; adequando-o aos ditames da Carta de Nova Iorque. De fato, as questões existenciais devem ser preservadas na maior medida do possível para o âmbito da autodeterminação da pessoa, ainda que ela seja deficiente mental ou intelectual, incluindo as questões de saúde.

Entretanto, observa-se que na prática, a equipe multidisciplinar que avalia a deficiência, nos termos do artigo $2^{\circ}$, PU do Estatuto, pode concluir pela inexistência total de possibilidade de manifestação de vontade, tanto para atos patrimoniais quanto para atos existenciais, para somente aqueles ou para somente estes. Ademais, essa equipe pode ainda entender, da análise minuciosa da situação casuística da pessoa pela incapacidade parcial, com a delimitação de atos patrimoniais e pessoais para os quais a pessoa não tem discernimento/possibilidade de expressão de vontade. Todas essas hipóteses serão, nos termos do Estatuto da Pessoa com Deficiência, excepcionalidades. Tanto é assim, que o parágrafo segundo do artigo $85^{10}$ do Estatuto determina que o juiz deve trazer a fundamentação em sentença que, como se entende, deve se basear nos estudos perpetrados pela equipe multidisciplinar.

O termo curatela vem de cura, do verbo curar, agregado ao sufixo do verbo curare que significa cuidar, olhar, velar (FIGUEIREDO; FANAN, 2003, p. 136).

A curatela é um instituto protetivo e assistencial (DIAS, 2011, p.621) aos maiores de idade (com 18 - dezoito - anos completos ou mais), contudo incapazes, sem condição de, por si só, exercerem os atos da vida civil. Os curatelados têm personalidade jurídica e capacidade de direito ou gozo, mas não têm a capacidade de fato ou de exercício, necessitando, assim, a depender do tipo de incapacidade, de um representante ou assistente - curador. Aos menores,

\footnotetext{
${ }^{9}$ Art. 85. A curatela afetará tão somente os atos relacionados aos direitos de natureza patrimonial e negocial. $\S 1$ o A definição da curatela não alcança o direito ao próprio corpo, à sexualidade, ao matrimônio, à privacidade, à educação, à saúde, ao trabalho e ao voto. [...]. (BRASIL, 2016).

${ }^{10}[\ldots]$ \& 20 A curatela constitui medida extraordinária, devendo constar da sentença as razões e motivações de sua definição, preservados os interesses do curatelado. [...]. (BRASIL, 2016).
} 
ainda que a incapacidade não derive da idade, aplicam-se os institutos do poder familiar, da guarda e da tutela.

Logo, a curatela justifica-se pela falta de discernimento ou possibilidade de expressão de vontade para o exercício dos atos civis, ou seja, pela falta de capacidade civil plena. A pessoa deve, efetivamente, não apresentar uma condição adequada de autodeterminação. Afinal, a capacidade é presumida, enquanto a incapacidade deve ser comprovada diante do caso concreto, via processo judicial de curatela/interdição.

Logo, o que se deve aferir é a falta de discernimento ou possibilidade expressão de vontade, de capacidade de autodeterminação para exercício da autonomia privada. De fato, conclui-se que o Código Civil não define quem tem ou não discernimento ou possibilidade de expressão de vontade para os atos da vida civil. "A detecção da presença e do grau de discernimento, então, é uma tarefa exclusiva do psiquiatra forense, que deverá se valer de seu instrumento técnico [...].” (TABORDA; MECLER; FRIDMAM; MORAES, 2004, p. 182). Na visão social da deficiência não bastará o laudo psiquiátrico, demandando avaliação de outros/as profissionais da saúde, como psicólogos/as, assistentes sociais, terapeutas ocupacionais, juristas etc. acerca da possibilidade de expressão de vontade.

Ressalta-se, contudo, que a curatela é um meio de substituição de vontade da pessoa que não apresenta possibilidade total ou parcial de expressão de vontade. E essa visão foi rechaçada pela Carta de Nova Iorque, conforme visto na seção 4, ao estabelecer que os Estados parte da Convenção devem reconhecer que as pessoas com deficiência têm capacidade legal em igualdade de condições com as demais pessoas em todos os aspectos da vida. Assim, os direitos humanos das pessoas com deficiência demandam, se necessário, medidas de apoio à toma de decisões e não medidas de substituição de vontade, confirmando, portanto, a capacidade delas.

Fato é que a teoria das incapacidades clássica foi construída sob a égide do individualismo e do patrimonialismo (SÁ; MOUREIRA, 2012, 169), preocupando-se em proteger o mais amplamente possível o patrimônio do incapaz. Hodiernamente, com a dignidade humana alocada no centro do ordenamento jurídico, as situações existenciais, como a saúde, têm que ser levadas em conta quando da curatela/interdição de uma pessoa. E sendo a pessoa competente para determinar seu conceito de vida boa, não há que lhe ser tolida esta oportunidade, garantindo-se, assim, iguais liberdades fundamentais (HABERMAS, 2003, p.128-131). 
Nesse contexto, se reconhecida for, de forma excepcional, a atuação do curador este não pode limitar o exercício da autonomia privada devidamente discernida pelo curatelado, quando sua capacidade de autodeterminação e competência para decisões acerca de sua vida forem devidamente reconhecidas pela medicina no caso concreto. Ademais, pela sistemática da teoria das capacidades após o Estatuto da Pessoa com Deficiência, a curatela, como medida excepcional, não poderá incidir sobre as questões existências.

Assim, tem-se que, quanto ao exercício da autonomia existencial junto às diretivas antecipadas de vontade pela pessoa com deficiência: a) ela é plenamente capaz, por estar habilitada à expressão de vontade e competência, razão pela qual pode livremente fazer duas diretivas antecipadas de vontade; b) caso a pessoa com deficiência capaz necessite de auxílio para elaborar suas diretivas antecipadas de vontade, poderá valer-se da Tomada de Decisão Apoiada - TDA, nos termos do artigo 1783-A do Código Civil; c) caso a pessoa com deficiência seja, excepcionalmente, curatelada, o curador não pode agir junto ás questões existenciais, de modo que a pessoa com deficiência pode realizar suas diretivas antecipadas livremente; e d) caso se reconheça, excepcionalmente, que a pessoa com deficiência não tem capacidade de expressão de vontade para as questões existenciais, a atuação do curador não se legitima em substituição de vontade a não ser na reconstrução da vontade da própria pessoa.

\section{CONSIDERAÇÕES FINAIS}

A inclusão da pessoa com deficiência, em especial o exercício de direitos existenciais e a extinção da "morte civil" do ordenamento brasileiro são realidades trazidas pelo Estatuto da Pessoa com Deficiência. Afinal, a deficiência, por si só, não é causa de incapacidade e a curatela não pode incidir sobre questões envolvendo o direito da personalidade das pessoas com deficiência (questões existenciais)

A pessoa, ainda que considerada incapaz pelo Código Civil, nem sempre será desprovida de discernimento ou possibilidade de expressão de vontade e competência para decidir acerca de suas questões existenciais, dentre elas aquelas que envolvem tratamento e procedimento médicos.

Se assim se entende, também assim se entenderá quando se tratar da possibilidade de se determinar tratamentos e procedimentos aos quais a pessoa deseja ou não se submeter no 
caso de vir a perder totalmente o discernimento ou a possibilidade de expressão de vontade no futuro.

Assim, as diretivas antecipadas de vontade são passíveis de utilização pelas pessoas, ainda que com deficiência, desde que gozem do discernimento ou possibilidade de expressão de vontade e da competência para as decisões médicas.

Ademais, também se admite que, diante da existência do mesmo discernimento ou possibilidade de expressão de vontade e competência, possa a pessoa com deficiência utilizarse do mandato duradouro ou da tomada de decisão apoiada para, no caso de perda do discernimento ou da capacidade de expressão de vontade, que outra pessoa, que pode ser inclusive um/a possível curador/a, tome decisões acerca de sua saúde. Percebe-se, nesse caso, que a atuação de terceira pessoa não decorre da incapacidade determinada pela lei, mas pelo próprio exercício da autonomia privada existencial do dito incapaz. Não há substituição de vontade.

Trata-se de uma visão dentro da revisão das teorias das capacidades civis que privilegia a construção da personalidade da pessoa com deficiência e lhe confere a dignidade humana por meio da garantia de iguais liberdades fundamentais, corolário da autonomia privada existencial biojurídica.

\section{REFERÊNCIAS}

ALMEIDA, Renata Barbosa de; RODRIGUES JÚNIOR, Walsir Edson. Direito civil: famílias. 2.ed. São Paulo: Atlas, 2012. 588p.

AMARAL, Francisco. 2006. Direito civil: introdução. 6. ed. Rio de Janeiro: Renovar, 662p.

ARAÚJO, Luiz Alberto David; NUNES, Lydia Neves Bastos Telles. Relativização da incapacidade para a prática de negócios jurídicos patrimoniais: a necessária aplicação dos vetores constitucionais. In.: EHRHARDT JR., Marcos; BARROS, Daniel Conde (Org.). Temas de Direito Civil Contemporâneo: estudos sobre o Direito das Obrigações e contratos, em homenagem ao professor Paulo Luiz Netto Lôbo. Salvador: Editora JusPodivm, 2009. P. 43-60.

BRASIL. Constituição da República Federativa do Brasil de 1988. Disponível em: <http://www.planalto.gov.br/ccivil_03/constituicao/constituicao.htm>. Acesso em: 01 Maio 2020.

BRASIL. Decreto n. 6.949, de 25 de agosto de 2009. Promulga a Convenção internacional sobre os Direitos das Pessoas com Deficiência e seu Protocolo Facultativo, assinados em Nova York, em 30 de marco de 2007. Disponível em: 
<http://www.planalto.gov.br/ccivil_03/_Ato2007-2010/2009/Decreto/D6949.htm>. Acesso em: 01 Maio 2020.

BRASIL. Lei n. 10.406, de 10 de janeiro de 2002. Institui o Código Civil. Disponível em: <http://www.planalto.gov.br/ccivil_03/LEIS/2002/L10406.htm>. Acesso em: 26 Jun. 2013.

BRASIL. Lei n. 13.146, de 6 de julho de 2015a. Institui a Lei Brasileira de Inclusao da Pessoa com Deficiencia (Estatuto da Pessoa com Deficiência). Disponível em: <http://www.planalto.gov.br/ccivil_03/_Ato2015-2018/2015/Lei/L13146.htm>. Acesso em: 10 Maio 2020.

BRASIL. Ministério da Mulher, da Família e dos Direitos Humanos/Secretaria Nacional dos Direitos da Pessoa com Deficiência. Resolução n. ${ }^{0}$ 01/2020. Disponível em: <http://www.in.gov.br/en/web/dou/-/z...-247019818>. Acesso em: 02 Maio 2020.

CATEB. Salomão de Araújo. Direito das Sucessões. 6.ed. São Paulo: Atlas, 2011. 469p.

CONSELHO FEDERAL DE MEDICINA. Resolução n. 1.995, de 31 de agosto de 2012. Dispõe sobre as diretivas antecipadas de vontade dos pacientes. Disponível em: <http://www.portalmedico.org.br/resolucoes/CFM/2012/1995_2012.pdf >. Acesso em: 01 Maio 2020 .

DIAS, Maria Berenice. Manual de Direito das Famílias. 8.ed. São Paulo: Editora Revista dos Tribunais, 2011. 688p.

FARIA, Roberta Elzy Simiqueli de. Autonomia da vontade e autonomia privada: uma distinção necessária. In.: FIUZA, César; SÁ, Maria de Fátima Freire de; NAVES, Bruno Torquato de (Coord.). Direito Civil: Atualidades II. Belo Horizonte: Del Rey, 2007. p.55-71.

FARIA, Romário. Parecer n. 266, de 2015. Substitutivo da Câmara dos Deputados n. 4, de 2015, ao Projeto de Lei do Senado n. 6, de 2003 (Projeto de Lei n. 7.699, de 2006, na Câmara dos Deputados), do Senador PAULO PAIM, que institui o Estatuto da Pessoa com Deficiência - Lei Brasileira da Inclusão. Disponível em: <http://www.senado.leg.br/atividade/rotinas/ materia/getDocumento.asp?t=167218>.

Acesso em: 22 Dez. 2015.

FIGUEIREDO, Isabella Ribeiro de; FANAN, Miriam Tridico. Curatela e interdição no novo Código Civil: inovações do instituto. Revista Síntese de Direito Civil e Processual Civil, v.4, n.22, p.136-140, mar./abr. 2003.

FIUZA, César. 2007. Direito Civil: curso completo. 10.ed. Belo Horizonte: Del Rey, 1112p.

GAGLIANO, Pablo Stolze; PAMPLONA FILHO, Rodolfo. 2009. Novo curso de direito civil: volume 1, parte geral. 11. ed. São Paulo: Saraiva, 499p.

HABERMAS, Jürgen. Direito e democracia: entre facticidade e validade. 2.ed. v.1. Rio de Janeiro: Tempo Brasileiro, 2003. p.128-131. 
LISBÔA, Natalia de Souza; SOUZA, Iara Antunes de. AUTONOMIA PRIVADA E COLONIALIDADE DE GÊNERO. In.: DIAS, Renato Duro; TAVARES, Silvana Beline; GUIMARÃES, Sandra Suely Moreira Lurine (Orgs.). Gênero, sexualidades e direito [Recurso eletrônico on-line]. organização CONPEDI/CESUPA. Florianópolis: CONPEDI, 2019. Disponível em: <

http://conpedi.danilolr.info/publicacoes/048p2018/qxo35b07/iUwptRd3eP509O5O.pdf>. Acesso em: 29 Abr. 2020. p.7-22.

MINAS GERAIS. Tribunal de Justiça do Estado. Apelação Cível 1.0427.13.001117-9/001. Relator Des.Wilson Benevides. Órgão Julgador: $7^{\mathrm{a}}$ Câmara Cível. Data de Julgamento: 25/04/2017. Disponível em: <www.tjmg.jus.br>. Acesso em: 10 Out. 2017.

MOREIRA, Luiza Amélia Cabus; OLIVEIRA, Irismar Reis de. Algumas questões éticas no tratamento da anorexia nervosa. Jornal de Psiquiatria, Rio de Janeiro, v. 57, n. 3, 2008.

Disponível em: <http://www.scielo.br/pdf/jbpsiq/v57n3/01.pdf〉. Acesso em: 01 Maio 2020.

NOGUEIRA; Roberto Henrique Pôrto; SOUZA, Iara Antunes de. PESSOA COM DEFICIÊNCIA: O DIREITO AO CASAMENTO A PARTIR DA ABORDAGEM DAS VULNERABILIDADES. In.: CARDIN; Valéria Silva Galdino; SILVA, João Vitor Penna e. (Orgs.). Direito de família e das sucessões [Recurso eletrônico on-line] organização CONPEDI/CESUPA. Florianópolis: CONPEDI, 2019.

ORGANIZAÇÃO MUNDIAL DA SAÚDE. CID-10 - Classificação Estatística Internacional de Doenças e Problemas Relacionados à Saúde. Décima Revisão. Versão 2008. Disponível em: <http://www.datasus.gov.br/cid10/v2008/cid10.htm >. Acesso em: 20 jun. 2013.

PENALVA, Luciana Dadalto. Declaração prévia de vontade do paciente terminal. Revista Bioética, Brasília: Conselho Federal de Medicina, v. 17, n. 3, 2009. p. 523-543.

POMPEU, Renata Guimarães. Autonomia privada na relação contratual. Belo Horizonte: Editora D'Plácido, 2015. 195p.

SÁ, Maria de Fátima Freire de; MOUREIRA, Diogo Luna. A capacidade dos incapazes: saúde mental e uma releitura da teoria das incapacidades no Direito Privado. Rio de Janeiro: Lumen Juris, 2011. 174p.

SÁ, Maria de Fátima Freire de; MOUREIRA, Diogo Luna. Autonomia para morrer: eutanásia, suicídio assistido e diretivas antecipadas de vontade. Belo Horizonte: Del Rey, 2012. $222 \mathrm{p}$.

SÁ, Maria de Fátima Freire de; NAVES, Bruno Torquato de Oliveira. Bioética e Biodireito. 4.ed. Belo Horizonte: Del Rey, 2018. 472p.

SÁ, Maria de Fátima Freire de; NAVES, Bruno Torquato de Oliveira. A relação médico paciente e as diretivas antecipadas de vontade. Informativo CEBID, n. 8, dez. 2012. p.1-3. Disponível em: <http://www.cebid.com.br/doc_newsletter/informativo8_dez12.pdf>. Acesso em: 15 jul. 2013. 
SÁ, Maria de Fátima Freire de. Personalidade Civil do Ser Humano e Direitos da Personalidade. Revista da Faculdade Mineira de Direito, Belo Horizonte, v.3, n.5 e 6, p.192$204,1^{\circ}$ e $2^{\circ}$ sem. 2000.

SOUZA, Iara Antunes de. Aconselhamento genético e responsabilidade civil: as ações por concepção indevida (wrongful conception), nascimento indevido (wrongful birth), vida indevida (wrongful life). Belo Horizonte: Arraes Editores, 2014. 150p.

SOUZA, Iara Antunes de. As diretivas antecipadas de vontade diante da curatela: (Im)possibilidade de exercício da autonomia privada do incapaz. In: DADALTO, Luciana (Org.). Diretivas antecipadas de vontade: ensaios sobre o direito à autodeterminação. 1ed.Belo Horizonte: Letramento, 2013, v. 1, p. 231-245.

SOUZA, Iara Antunes de. Estatuto da Pessoa com Deficiência: curatela e saúde mental. 1. ed. Belo Horizonte: D'Plácido Editora, 2016. v. 1. 464p .

SOUZA, Iara Antunes de Souza. Reflexões sobre os impactos do Estatuto da Pessoa com Deficiência no Direitos das Famílias: curatela e casamento. In.: PEREIRA, Fábio Queiroz; MORAIS, Luísa Cristina de Carvalho; LARA, Mariana Alves (Orgs.). A teoria das incapacidades e o estatuto da pessoa com deficiência. 2.ed. Belo Horizonte: Ed. D'Plácido, 2018. p.203-217.

SOUZA, Iara Antunes de. O CASAMENTO DAS PESSOAS COM DEFICIÊNCIA MENTAL NO BRASIL: Identidade, cultura e família.. Conpedi Law Review, v. 4, p. 276-296, 2018.

TABORDA, José G. V.; MECLER, Kátia; FRIDMAN, Sander; MORAES, Talvane de. Avaliação da capacidade civil e perícias correlatas. In.: TABORDA, José G. V.; CHALUB, Miguel; ABDALLA-FILHO, Elias (Org.). Psiquiatria Forense. Porto Alegre: Armed, 2004. p.177-314.

TAVARES, Fernando Horta; SOUZA, Iara Antunes de; BONTEMPO, Tiago Vieira; LIBRELON, Kellen Fonseca; SALIBA, Dantte Cunha Melo. Diretivas antecipadas e autonomia privada: adequabilidade junto ao ordenamento jurídico brasileiro. No prelo.

TEIXEIRA, Ana Carolina Brochado; RIBEIRO, Gustavo Pereira Leite. Procurador para cuidados de saúde do idoso. In.: PEREIRA, Tânia da Silva; OLIVEIRA, Guilherme de (Coord.). Cuidado e vulnerabilidade. São Paulo: Atlas, 2009. p.1-16.

TEIXEIRA, Ana Carolina Brochado; RODRIGUES, Renata de Lima. O direito das famílias entre a norma e a realidade. São Paulo: Atlas, 2010. 255p.

TEIXEIRA, Ana Carolina Brochado. Autonomia existencial. Revista Brasileira de Direito Civil - RBDCivil | Belo Horizonte, v. 16, p. 75-104, abr./jun. 2018. P.75-104.

TEIXEIRA, Ana Carolina Brochado; SOUZA, Iara Antunes de. Algumas reflexões sobre a limitação da curatela às questões patrimoniais no Estatuto da Pessoa com Deficiência. In: LIMA, Taisa Maria Macena de; SÁ, Maria de Fátima Freire de; MOUREIRA, Diogo Luna 
(Org.). Autonomia e vulnerabilidade. 1ed.Belo Horizonte: Arraes Editores, 2017, v. 1, p. 154167. 